\title{
PENINGKATAN STATUS LANAL RANAI MENJADI LANTAMAL: STRATEGI INDONESIA SEBAGAI ANTISIPASI ANCAMAN CHINA DI NATUNA
}

\author{
Raden Mas Jerry Indrawan \\ UPN"Veteran "Jakarta \\ jerry_indrawan18@yahoo.co.id
}

\begin{abstract}
Abstrak
Bertambahnya kekuatan China di segala sektor, terutama ekonomi, dan tentu saja militer, negara ini makin agresif dalam mengembangkan wilayahnya. Sebagai hasilnya, sengketa di Laut China Selatan (LCS) antara China dengan 5 negara ASEAN, dan juga Taiwan, merembet ke wilayah Indonesia, tepatnya di Natuna. Kepulauan Natuna memang memiliki daya tarik bagi negara-negara lain karena potensi sumber daya alamnya yang sangat besar dan lokasinya yang strategis. Untuk menghadapi ancaman China, yang jika terjadi perang di Natuna pasti akan dilakukan melalui laut, maka tulisan ini menyarankan agar meningkatkan status Pangkalan Angkatan Laut (Lanal) Ranai di Natuna menjadi Pangkalan Utama Angkatan Laut (Lantamal). Eskalasi ancaman dari LCS membuat Indonesia harus mempunyai basis pertahanan laut yang kuat, yang menghadap langsung dengan LCS. Sejauh ini, Indonesia baru memiliki 14 Lantamal yang dibagi ke dalam dua komando utama armada, yaitu Komando Armada RI Kawasan Barat (Koarmabar) dan Komando Armada RI Kawasan Timur (Koarmatim). Dengan visi Poros Maritim Dunia, 14 Lantamal dengan wilayah seluas Indonesia ini tentunya masih sangat kurang. Tulisan ini juga ingin melihat kaitan antara Angkatan Laut dengan Angkatan Udara dalam konsep maritime based defense. Konsep ini mengkolaborasikan kekuatan Angkatan Laut dengan Angkatan Udara, karena faktor geografis negara kepulauan membutuhkan respons cepat. Untuk itulah, pentingnya sinergi antara AL dengan AU terlihat dari peran Lanud Ranai di Natuna, Lanud Roesmin Nurjadin di Pekanbaru, dan Lanud Supadio di Pontianak, untuk mendukung keberadaan Lantamal Ranai nantinya.
\end{abstract}

\section{Kata Kunci:}

\section{Lantamal Ranai, Lanud Ranai, Kekuatan Militer, dan Ancaman China}

\begin{abstract}
The growing strength of China in all sectors, especially economy, and of course military, the country is increasingly aggressive in expanding its territory. As a result, the dispute in the South China Sea (SCS) between China and the five ASEAN countries, as well as Taiwan, spread to Indonesia, especially in Natuna. The Natuna Islands have an appeal to other countries because of its enormous natural resource and strategic location. To deal with the Chinese threat, which in case of war in Natuna will surely be done by sea, then this paper suggests to increase the status of Navy Base (Lanal) Ranai in Natuna into Navy Main Base (Lantamal). The escalation of threats from SCS makes Indonesia must have a strong sea defense base, facing directly to the SCS. So far, Indonesia only has 14 Lantamal, which is divided into
\end{abstract}


two main command of the fleet, West Region Fleet Command (Koarmabar) and East Region Fleet Command (Koarmatim). With the vision of the World Maritime Fulcrum, 14 Lantamal with an area large as Indonesia, is certainly not enough. This paper also wants to see the link between the Navy and the Air Force in the concept of maritime based defense. This concept collaborates Navy and Air Force forces, due to geographical factors of the archipelagic state requires quick response. For that reason, the importance of synergy between Navy and Air Force seen from the role of Ranai Air Force Base in Natuna, Roesmin Nurjadin Air Force Base in Pekanbaru, and Supadio Air Force Base in Pontianak, to support Lantamal Ranai.

\section{Keywords:}

Ranai Navy Main Base, Ranai Air Force Base, Military Power, China's Threat

\section{Pendahuluan}

Salah satu sengketa yang sedang panas diperbincangkan di dunia internasional saat ini adalah sengketa antara China, Taiwan, dan 4 negara ASEAN, yaitu Filipina, Brunei Darussalam, Vietnam, dan Malaysia di Laut China Selatan (LCS). Negaranegara tersebut menjadi negara claimant terkait klaim masing-masing negara terhadap batas laut wilayahnya. Sekalipun Kepulauan Natuna di Indonesia tidak temasuk klaim dari salah satu negara, yaitu China, akan tetapi dampaknya ternyata sampai ke salah satu kepulauan terluar di wilayah Indonesia tersebut.

$$
\text { Dengan semakin }
$$

bertambahnya kekuatan China di segala sektor, terutama ekonomi dan tentu saja militer, negara ini makin agresif dalam mengembangkan wilayahnya. Secara teori, sebuah negara yang mulai mendapatkan power besar, terutama dalam percaturan politik internasional, akan mulai meninggalkan regulasi-regulasi internasional. Mereka akan mulai secara halus dulu "menabrak" aturanaturan tersebut demi kepentingan nasionalnya. Setelah itu, langkahlangkah militer yang agresif bisa saja dilakukan. Semuanya karena China sekarang memiliki power yang besar (Kompas, 2016).

Jalur laut yang paling strategis di kawasan Asia Timur dan Asia Pasifik adalah Laut China Selatan. Jalur ini sangat penting bagi perdagangan internasional. Karena itu, upaya China membuat pulau buatan di Kepulauan Spratly pastilah memiliki motivasi ekonomi yang terkait klaim mereka di wilayah itu. Nilai instrinsik Kepulauan Spratly memang sangat kecil, tetapi landasan di bawah Spratly 
diketahui sangat kaya akan minyak, gas, dan berbagai sumber daya laut lainnya. Perkiraan tentang ketersediaan minyak dan gas berkisar di antara 1-2 miliar, sampai 225 miliar barrel (Luhulima, 2011: 170).

Wilayah di Kepulauan Spratly mencakup lebih dari 750 batu karang, atol dan pulau-pulau kecil, di lepas pantai Filipina, Malaysia, dan Vietnam. Banyaknya sumber daya alam memang membuat wilayah perairan ini menjadi seksi bagi negaranegara disekitarnya. Di Kepulauan Spratly terdapat sebuah gugusan karang yang bernama Subi, terletak 660 mil dari pantai Tiongkok. Gugusan karang yang terendam di bawah laut ini ditambahi beton, lalu dibuat seperti pulau buatan seluas 2000 hektar. Pulau buatan ini dapat mengakomodir landasan pacu pesawat terbang sejauh 3000 meter. Setelah selesai dibangun, landasan pacu ini dapat didarati oleh hampir semua jenis pesawat terbang yang dimiliki militer China saat ini. Menurut kabar, ada dua bagian landasan pacu sepanjang 468 meter dan 200 meter yang masih dalam tahap pembangunan (Suara Karya, 2015).
China telah melanggar ketentuan terhadap hukum laut internasional (UNCLOS), sehingga pembuatan pulau buatan di Kepulauan Spratly pun tidak memiliki legitimasi. Mereka melanggar norma-norma yang mengarisbawahi arsitektur keamanan di Asia Timur, serta konsensus regional yang mengedepankan diplomasi dan menentang tindakan koersif. Sebuah ancaman militer? Bisa jadi. Potensi terjadinya gesekan dengan negara-negara penuntut di Laut China Selatan lainnya sangat besar. Kegiatan "memancing" garagara ala China ini sudah pasti akan meningkatkan eskalasi konflik yang sebelumnya sudah memanas (Kompas, 2016). Selain itu, urgensi China di Natuna adalah terkait kepentingan geopolitiknya di Asia Timur dan Asia Tenggara, termasuk sengketa di Laut China Selatan. Sumber daya alam dan nilai strategis Natuna yang tinggi membuat China tidak bisa berpaling dari kepulauan tersebut.

Bicara sejarah Natuna, Kepulauan Natuna sebetulnya masuk dalam wilayah Kerajaan Pattani dan Kerajaan Johor di Malaysia. Namun, pada abad ke-19 Kesultanan Riau menjadi penguasa pulau yang berada 
di jalur strategis pelayaran internasional tersebut. Setelah Indonesia merdeka, delegasi dari Riau ikut menyerahkan kedaulatan pada republik yang berpusat di Jawa. Pada 18 Mei 1956, Indonesia resmi mendaftarkan kepulauan itu sebagai wilayahnya ke PBB. Sempat ada kajian dari akademisi Malaysia, bahwa Natuna secara sah seharusnya milik Negeri Jiran. Namun, untuk menghindari konflik lebih panjang setelah era konfrontasi pada 19621966, maka Malaysia tidak menggugat status Natuna (Jakarta Greater, 2015).

\section{Kepulauan Natuna memang} memiliki daya tarik bagi negaranegara lain karena potensi sumber daya alamnya yang sangat besar. Menurut data resmi Pemerintah Daerah Kabupaten Natuna, kawasan Natuna memiliki sumber kekayaan perikanan laut yang hasilnya bisa mencapai lebih dari 1 juta ton/tahun, dan ladang gas blok D-Alpha yang terletak $225 \mathrm{~km}$ di sebelah utara Pulau Natuna (di ZEEI) dengan total cadangan 222 trillion cubic feet (TCT) dan gas hidrokarbon yang bisa didapat sebesar 46 TCT merupakan salah satu sumber cadangan gas alam terbesar di
Asia (Pemerintah Daerah Kabupaten Natuna, 2015).

Alasan China "mengorekngorek" wilayah Natuna adalah karena mereka menganggap wilayah Natuna adalah zona penangkapan ikan tradisional mereka (traditional fishing zone) sejak ratusan tahun yang lalu (Maritime Awarenes Project, 2016). Potensi sumber daya alam di kawasan Natuna yang sangat besar tersebut diduga kuat menjadi salah satu faktor utama yang mempengaruhi intensi China dalam upanya mencoba "bermain" di wilayah Natuna, sekalipun dalam klaim nine dash line mereka, Natuna tidak dimasukkan.

Beberapa waktu terakhir ini, China mulai terlihat untuk "menguasai" Natuna. Hal ini ditandai dengan banyaknya kapal nelayan mereka, maupun kapal-kapal patroli penjaga pantainya, yang melanggar masuk ke wilayah Natuna (ABC, 2016). Kondisi ini menyebabkan tensi antara kedua negara meningkat di level internasional. Untuk menghadapi kemungkinan ancaman dari China di Natuna, termasuk ancaman militer tentunya, dirasa perlu bagi Indonesia untuk mempersiapkan langkahlangkah pengamanan. 
Dalam tulisan ini, penulis mengusulkan untuk ditingkatkannya pangkalan militer yang sudah ada, termasuk ditambah beberapa pangkalan militer untuk Angkatan Laut (AL) sebagai basis utama pertahanan dan pengamanan wilayah kedaulatan kita di Natuna. Satu pangkalan militer AL sudah ada di Ranai, yaitu Pangkalan Angkatan Laut (Lanal) Ranai. Sekedar informasi, Lanal Ranai berada di bawah Pangkalan Utama IV (Lantamal IV) di Tanjungpinang, yang juga membawahi 5 Lanal, yaitu Batam, Tarempa, Tanjung Balai Karimun, dan Dabo Singkep. Lanal Ranai berlokasi di Ranai, Ibukota Kabupaten Natuna yang berbatasan langsung dengan Laut China Selatan.

Topik ini dipilih karena penulis ingin agar Lanal Ranai ditingkatkan statusnya menjadi Pangkalan Utama Angkatan Laut (Lantamal) dengan tujuan untuk menghadapi kemungkinan serangan militer di daerah Kepulauan Natuna, yang ditenggarai bisa datang dari China. Peningkatan ini sekaligus menambah tiga Lanal di bawahnya, yang akan dibangun di pulau-pulau terluar Kepulauan Natuna, yaitu di
Pulau Sekatung, Pulau Subi Kecil, dan Pulau Kepala. Sekalipun Indonesia memang sedang membangun pangkalan militer, sesuai rencana strategis lima tahunan TNI 2015-2019, akan tetapi penulis merasa peningkatan status Lanal Ranai menjadi Lantamal, termasuk pembangunan Lanal di tiga pulau terluar di Natuna harus menjadi prioritas karena ancaman dari China yang meningkat di wilayah tersebut. Atas dasar itulah, tulisan ini ingin menjelaskan tentang upaya Indonesia mengamankan wilayah kedaulatan kita di Kepulauan Natuna dengan meningkatkan status Lanal Ranai menjadi Lantamal, termasuk membangun tiga Lanal baru tersebut.

\section{China Sebagai Ancaman}

Di awal tulisan ini, ada baiknya kita melihat potensi ancaman yang akan muncul terhadap kedaulatan wilayah kita di Natuna, termasuk di kawasan Asia Tenggara secara umum. Sudah jelas jika China adalah ancaman utama kita di Natuna, yang muncul dari ekses pertarungan wilayah di Laut China Selatan. Untuk itu, di bagian ini kita akan melihat bagaimana China dapat dipandang sebagai sebuah ancaman terhadap 
Natuna, kemudian di bagian-bagian selanjutnya akan dirumuskan bagaimana cara kita menghadapi ancaman tersebut.

Bicara ancaman, kita dapat membaginya ke dalam dua kategori, yaitu ancaman terhadap individu dan ancaman terhadap kelompok individu. Ancaman terhadap kelompok individu lebih banyak dipelajari dalam konteks hubungan internasional. Ancaman jenis ini dapat terjadi dalam bentuk ancaman militer, ancaman ekonomi, atau ancaman budaya (Rousseau dan Garcia-Retamero, 2001: 745). Ancaman ekonomi terlihat dari investasi besar-besaran China di Indonesia yang secara tidak langsung pasti mengaruhi iklim pembuatan kebijakan di Indonesia. Sebagai sebuah negara besar, China memiliki tujuan-tujuan strategis untuk meningkatkan kekuatan negaranya. Keunggulan utama China adalah jumlah populasinya yang mencapai 1.3 miliar. Dengan populasi yang besar, China memiliki sumber daya melimpah untuk melakukan pembangunan, baik sektor ekonomi maupun militer (Wirawan dan Subekti, 2012: 32).
Saat ini China adalah negara dengan kekuatan militer terbesar kedua di dunia. Jika kita bandingkan dengan Indonesia, menurut situs Global Fire Power (GFP), total kekuatan armada laut China mencapai 714 kapal, sedangkan Indonesia hanya 221 kapal. China berada di urutan kedua dunia di bawah Korea Utara, sedangkan Indonesia berada di urutan kesepuluh. Sedangkan, di urutan GFP secara umum, China berada di urutan ketiga negara dengan kekuatan militer terbesar di dunia (di bawah AS dan Rusia), dan Indonesia berada di urutan keempat belas (Global Fire Power, 2016). Jika diskenariokan kedua negara bertemu di medan perang, maka di atas kertas China akan jauh lebih unggul.

Selain memiliki jumlah personil militer yang besar, China juga didukung oleh kekuatan alutsista yang mumpuni dan siap diterjunkan ke medan perang. Faktor militer inilah yang menjadi variabel utama, yang dapat memberikan ancaman bagi Indonesia. Dengan postur kekuatan militer yang besar dan didukung kekuatan alutsista, China dapat menerjunkan kekuatan militernya untuk menjaga kepentingan 
negaranya, termasuk terlibat dalam setiap konflik di mana China menjadi aktornya ((Wirawan dan Subekti, 2012: 34).

Faktor jarak dan kedekatan juga dapat menunjukkan ancaman China terhadap Indonesia. Proyeksi terhadap gelar pasukan China dapat memberikan level ancaman tersendiri terhadap negara-negara yang berdekatan maupun berada dalam kawasan yang dapat dijangkau dari gelaran pasukan tersebut. Gelaran Armada Laut Selatan China berpusat di Zhanjiang, sebuah kota yang berhadapan langsung dengan LCS. Gelar kekuatan ini diproyeksikan untuk menjaga kepentingan China di Asteng dan LCS (Wirawan dan Subekti, 2012: 36).

Di Armada Laut Selatan ini terdapat 2 kapal selam penyerang berbahan bakal nuklir, satu kapal selam nuklir yang dilengkapi dengan rudal balistik, 14 kapal penyerang berbahan bakar diesel, 8 kapal perang kelas destroyer, 18 kapal frigate, 30 kapal amfibi, dan 33 kapal patroli cepat yang dilengkapi rudal. Potensi konflik masa depan di LCS, bisa jadi termasuk di Natuna, membuat Armada Laut Selatan menjadi gelar pasukan terdepan yang sewaktu-waktu bisa dikirim ke wilayah-wilayah tersebut (Wirawan dan Subekti, 2012: 37).

Selain kekuatan laut, kekuatan udara China juga memiliki kemampuan tinggi, termasuk mampu keluar dari teritori negaranya untuk melakukan serangan. Gelaran pasukan udara China yang mengarah langsung ke Asteng dan LCS terdapat di kota Guangzhou. Di sana terdapat lima divisi pesawat tempur dan satu divisi pesawat pembom. Selain itu, ditambah pula dengan dua divisi pesawat tempur dari Armada Laut Selatan di Zhanjiang. Dengan gelar pasukan di Guangzhou dan Zhanjiang, China dapat dengan cepat menerjunkan pesawat-pesawat tempur untuk menjaga kepentingan China, maupun melakukan invasi militer (Wirawan dan Subekti, 2012: 38).

Sebagai kekuatan dunia baru, China mengkonsentrasikan peningkatan kapasitas maritimnya dengan membangun kekuatan maritim yang berbasis kekuatan Blue Water Navy. Blue Water Navy adalah kekuatan Angkatan Laut yang beroperasi lintas samudera di laut lepas, jauh melebihi wilayah ZEE-nya sendiri. Angkatan Laut jenis ini harus 
memiliki armada laut dengan kemampuan maritim eksploratif (Speller, 2002: 374). Peningkatan kapasitas ini terlihat saat China meluncurkan kapal induknya yang pertama dan proyeksi rencana Second Island Chain. Rencana Second Island Chain ini terdiri dari Laut Jepang, Laut Filipina, Laut Indonesia, Kepulauan Kuril, Hokkaido, Mariana, dan Kepulauan Palau di selatan (Wirawan dan Subekti, 2012: 40).

\section{Second Island Chain dan} gelaran pasukan China yang berada dekat Asteng dan LCS menjadi ancaman nyata bagi negara-negara yang masuk di dalamnya, tentunya juga Indonesia. Dengan meningkatnya aksi China di Natuna membuat kita harus lebih waspada dan bersiap menghadapi ancaman tersebut secara lebih serius, karena terbukti jika China memang merupakan ancaman bagi Indonesia di Natuna. Pembahasan selanjutnya adalah tentang bagaimana Indonesia bersiap mengahadapi ancaman China di LCS.

\section{Peningkatan Status Lanal Ranai}

Ekses dari sengketa Laut China Selatan antara Beijing dengan Manila, Kuala Lumpur, Hanoi, Bandar
Sri Begawan, dan Taipei, membuat Natuna kena getahnya. Dengan sumber daya alam yang melimpah dan lokasinya yang strategis, sulit rasanya bagi China untuk "overlook" Natuna. Atas dasar itulah, kemungkinan terjadinya konflik, yaitu berupa agresi militer China di Natuna sangat mungkin terjadi. Jika terjadi, konfrontasinya tentunya akan terjadi di laut. Maka dari itu, Indonesia harus menyiapkan strategi terbaik untuk bersiap menghadapi kemungkinan terburuk tersebut. Dalam tempo singkat, mustahil untuk kita bisa menyamai, atau setidaknya mengimbangi kekuatan laut China jika komparasinya adalah seperti yang sudah dijelaskan di bagian sebelumnya. Untuk itu, langkahlangkah sementara perlu dilakukan, setidaknya untuk memberikan efek gentar (deterrence) kepada pihak lawan.

Efek gentar tersebut tentunya dapat diinterpretasikan sebagai gelar pasukan (military deployment). Sejauh ini kita melihat pemerintah, melalui TNI sudah mulai melakukan hal tersebut dengan mengirimkan pesawat tempur dan beberapa kapal perang di Lanud Ranai dan Lanal Ranai untuk 
menunjukkan kekuatan (show of force) kepada China. Akan tetapi, menurut penulis langkah tersebut belum optimal karena masih bersifat temporer. Perlu dibuat sebuah show of force yang permanen dari kekuatan militer kita kepada siapapun yang ingin memasuki atau menguasai wilayah di sekitar Natuna. Untuk itulah, penulis mengira diperlukan peningkatan status Lanal Ranai menjadi Lantamal agar proses unjuk kekuatan tadi dapat berjalan secara berkelanjutan dan memiliki efek gentar yang jauh lebih kuat.

Kehadiran pangkalan militer memang selalu menjadi cara terbaik sebuah negara untuk unjuk kekuatan militernya. Ambil contoh Amerika Serikat yang memiliki pangkalan militer tidak hanya di negaranya, tetapi di hampir seluruh dunia. Kondisi ini membuat negeri Paman Sam itu menjadi kekuatan militer terkuat di dunia, termasuk memiliki bargaining position yang sangat tinggi di kancah politik internasional. Jadi, kita melihat relasi yang signifikan antara kekuatan militer sebuah negara dengan posisi negara tersebut di mata dunia internasional. Diplomasi tanpa kekuatan militer adalah macan kertas belaka.

Kembali ke pembahasan mengenai peningkatan status Lanal Ranai, Lanal ini harus dibuat setara Lantamal (pangkalan kelas A), dengan tiga lanal yang dibangun persis di tiga pulau terluar Indonesia. Pulau-pulau tersebut adalah Pulau Sekatung, Pulau Subi Kecil, dan Pulau Kepala. Tiga pulau terluar Indonesia yang terletak di Kepulauan Natuna ini adalah pulaupulau terluar yang rawan masalah pertahanan dan keamanan. Untuk itu, demi menjaga kedaulatan negara pulau-pulau terluar tersebut harus diberdayakan. Ditambah, menurut Panglima TNI Gatot Nurmantyo, daripada membeli kapal induk lebih baik memberdayakan pulau-pulau terluar untuk menjalankan fungsi yang serupa kapal induk. Di pulau, pesawat tempur, pesawat transportasi, helikopter, dan lain-lain bisa juga mendarat (CNN Indonesia, 2016).

Langkah pemerintah yang telah menaikkan status Lanal Pontianak menjadi Lantamal (sekarang menjadi Lantamal XII) patut diapresiasi tinggi. Langkah ini dilakukan sebagai manuver untuk membentengi wilayah kita dari 
agresivitas China. Hanya saja, tidak akan cukup jika hanya ditambah satu Lantamal, sekalipun beberapa Lantamal yang sudah ada, yaitu Lantamal IV Tanjung Pinang Lantamal di Ranai nantinya akan menjadi Lantamal ke-15 yang dimiliki TNI AL dan berada di Komando Armada RI Kawasan Barat (Koarmabar).

Peningkatan status Lanal Ranai menjadi Lantamal adalah karena Kepulauan Natuna yang berada di wilayah Indonesia, sering mendapat ancaman atau gangguan keamanan dari bangsa asing. Mulai dari sengketa kepemilikan dengan Malaysia sampai sekarang dengan China. Hal ini tentunya karena sumber daya alamnya yang melimpah dan letaknya yang strategis secara geopolitik, seperti yang sudah disebutkan sebelumnya.

Kondisi ancaman yang demikian tinggi di Natuna membuat perubahan status Lanal Ranai menjadi Lantamal sangat diperlukan. Lantamal Ranai nantinya akan digunakan sebagai basis pertahanan pertama kita menghadapi ancaman militer yang mungkin saja muncul dari China. Masih lekat di ingatan kita bagaimana pada bulan Maret yang lalu, kapal penjaga pantai China melanggar kedaulatan wilayah Indonesia dengan masuk secara ilegal untuk menyelamatkan kapal nelayan mereka yang sebenarnya sudah ditangkap oleh aparat Indonesia. Kapal penjaga pantai China dengan sengaja menabrak kapal nelayan tersebut agar kapal Indonesia tidak dapat menariknya untuk kemudian disita. Peristiwa yang hampir sama juga terjadi pada bulanbulan berikutnya, di mana kapal-kapal nelayan China melanggar wilayah Indonesia dengan mencari ikan di wilayah Natuna (Nytimes, 2016).

Kondisi ancaman yang tinggi di Natuna adalah alasan kedua mengapa status Lanal Ranai harus ditingkatkan menjadi Lantamal. Sejauh ini, Indonesia baru memiliki 14 Lantamal yang dibagi ke dalam dua komando utama armada, yaitu Komando Armada RI Kawasan Barat (Koarmabar) dan Komando Armada RI Kawasan Timur (Koarmatim). Dengan visi Poros Maritim Dunia ala Presiden Jokowi, 14 Lantamal dengan wilayah seluas nusantara ini tentunya masih sangat kurang. Maka diperlukan sebuah grand design kebijakan pertahanan yang tidak lagi berorientasi pada darat (teritori). Strategi besar 
pertahanan kita sekarang harus diarahkan ke arah laut. Ancaman yang ada pun kebanyakan berhubungan dengan laut.

Setelah Lanal Ranai dianaikkan statusnya menjadi Lantamal, maka penulis mengusulkan untuk juga dibuat tiga Lanal yang berada di bawah Lantamal Ranai, katakanlah Lantamal Ranai menjadi Lantamal ke-15. Tiga lanal yang dibentuk di bawah Lantamal 15 adalah Lanal Sekatung yang berada di pulau Sekatung, Lanal Subi Kecil yang berada di pulau Subi Kecil, dan Lanal Kepala yang berada di Pulau Kepala.

Pertama adalah Lanal Sekatung. Lanal ini akan ditempatkan di pulau Sekatung, yang adalah salah satu pulau terluar dan paling utara dari wilayah Provinsi Kepulauan Riau, dan masuk ke dalam Kabupaten Natuna. Pulau ini berbatasan langsung dengan Laut China Selatan, termasuk batas klaim China, yaitu nine dash line, yang menjadi sengketa di wilayah tersebut. Selain berbatasan dengan Laut China Selatan, Pulau Sekatung juga berbatasan dengan Vietnam.

Mengingat letak geografisnya, maka dapat dipastikan Pulau Sekatung bernilai strategis. Pulau ini, bersama pulau terluar lain, menjadi titik dasar dari garis pangkal kepulauan yang menentukan wilayah perairan Zona Ekonomi Eksklusif (ZEE) dan Landas Kontinen Indonesia. Sederhananya, Pulau Sekatung penting karena membentuk batas wilayah kedaulatan Indonesia. Hanya beberapa KK saja ditambah satu peleton personil TNI yang menjadi penduduk di pulau ini.

Kedua adalah Lanal Subi Kecil. Pulau Subi Kecil adalah pulau terluar Indonesia yang terletak di Laut Natuna, yang juga berbatasan dengan Laut China Selatan. Selain itu, pulau ini juga berbatasan dengan Malaysia bagian Timur. Pulau ini berpenduduk sekitar 3000 orang. Secara sejarah, dua penjajah kita melihat peran Subi Kecil sebagai sebuah pulau yang sangat strategis. Belanda pernah membuat mercusuar di sekitar pertengahan tahun 1800-an, kemudian dilanjutkan Jepang dengan membuat lapangan terbang di sekitar tahun 1944 (Antara Kepri, 2013).

Ketiga adalah Lanal Kepala. Pulau Kepala juga berbatasan langsung dengan Laut China Selatan dan Malaysia bagian Timur. Pulau ini menjadi salah satu pulau yang menjadi dasar acuan garis batas pulau-pulau 
terluar di Kepulauan Riau. Sebagai salah satu pulau terdepan, pulau ini tidak terlepas dari ancaman eksternal, seperti illegal fishing dan kemungkinan ancaman militer dari negara lain. Fakta bahwa pulau ini belum berpenghuni membuat siapapun yang ingin menyerang Indonesia secara militer dapat masuk melalui wilayah Pulau Kepala.

Hal ini yang menjadi concern penulis, sehingga penulis melihat urgensi agar di Pulau Kepala dibentuk pangkalan militer setingkat Lanal. Tidak adanya penduduk, apalagi tidak adanya personil TNI yang berjaga di pulau tersebut membuat pulau ini sangat rawan diduduki pihak asing (musuh). Jika katakanlah pulau ini dikuasai China, maka mereka bisa membuat pangkalan militer sementara untuk mendukung agresi militernya masuk ke dalam wilayah Indonesia. Posisinya yang juga berdekatan dengan Kalimantan Barat membuat jika ada agresi militer musuh, maka mereka bisa dengan mudah memasuki wilayah Kepulauan Riau dan juga Kalimantan, khususnya Kalbar.

Adanya satu Lantamal saja, yaitu Lantamal Pontianak tentunya tidak cukup menahan serbuan China, sekalipun Lanud Supadio sekarang sudah menjadi Lanud tipe A. Tipe tersebut menunjukkan bahwa Lanud Supadio saat ini memiliki 1 skuadron tempur dengan jumlah 18 pesawat, dan akan ditambah satu skuadron lagi secara bertahap. Diharapkan Lanud Supadio akan menjadi back-up bagi Lantamal Ranai nantinya, terutama dari segi kekuatan udara (air power).

Peningkatan status Lanai Ranai menjadi Lantamal juga pastinya akan menambah kekuatan TNI AL di kawasan bagian Barat dan Alur Laut Kepulauan Indonesia (ALKI) 1. Lantamal Ranai nantinya akan diperkuat oleh paling tidak satu dari tiga kapal selam TNI AL kelas Changbogo yang didatangkan dari Korea Selatan. Sementara, dua kapal selam lainnya masih dalam proses penyelesaian (Tempo, 2016).

Dengan proyeksi Minimum Essential Force (MEF) Renstra I sampai III, di mana TNI AL akan memiliki kapal selam sebanyak 12 unit, maka kemungkinan ditempatkannya minimal satu kapal selam di Lantamal Ranai sangat memungkinkan (Okezone, 2016). Jika ingin melihat dari konteks gelar kekuatan militer, kehadiran kapal 
selam di perbatasan laut sebuah negara, apalagi dalam kondisi eskalatif seperti di Natuna, memiliki efek detterence (gentar) yang cukup kuat. Apalagi, wilayah Natuna yang dekat dengan Laut China Selatan memang dikelilingi oleh laut dalam. Perairan laut dalam yang landas kontinennya mencapai 4000 meter sangat cocok untuk menyembunyikan kapal selam (BBC Indonesia, 2016). Bahkan, di masa depan perairan laut dalam seperti ini dapat digunakan sebagai basis kapal selam kita sebagai efek gentar tadi, maupun persiapan jika ada invasi militer dari negara lain.

Biasanya, di setiap Lantamal atau Lanal hanya memiliki kapal sekelas Offshore Patrol Vehicle (OPV) atau kapal patroli bersenjata. Akan tetapi, khusus untuk Lantamal Ranai penulis menyarankan harus ada sejumlah besar kapal korvet dan frigate, selain kapal patroli tadi, yang siap diluncurkan kapan saja jika ketegangan memuncak. Selain itu, KRI-KRI kita juga harus mengadakan patroli rutin, dengan dukungan udara juga tentunya.

Peningkatan status menjadi Lantamal juga berarti penambahan pasukan. Dengan demikian, di
Lantamal Ranai akan terdapat satu kompi Pasukan Marinir (Pasmar), empat unit Pasukan Khas (Paskhas) AU, dan satu batalion infanteri AD. Bahkan, menurut Panglima TNI Jenderal Gatot Nurmantyo, Indonesia harus menyebarkan sistem rudal pertahanan Oerlikon Skyshield di kawasan Natuna. Sistem rudal Oerlikon Skyshield adalah sistem pertahanan udara modular termasuk meriam multirole otomatis $35 \mathrm{~mm}$ yang dapat menembakkan 1.000 putaran per menit, serta proyektil berpresisi yang dapat menembak jatuh pesawat. Sistem ini sedang digunakan di Lanud Supadio, Halim Perdanakusuma, dan Hasanuddin (Sindo News, 2016). Terakhir, nantinya Lantamal ini akan mendapat dukungan udara, terutama dari Lanud Ranai di Natuna, dan Lanud-Lanud sekitarnya, seperti Lanud Roesmin Nurjadin di Pekanbaru dan Lanud Supadio di Pontianak.

Memberdayakan pulau-pulau terluar di Indonesia untuk dijadikan pangkalan militer sebenarnya jangan hanya dilihat sebagai langkah pengamanan untuk menhadapi China dan juga ancaman lainnya saja. Memberdayakan pulau-pulau terluar 
adalah bagian dari sistem pertahanan negara yang keberadaannya perlu dikelola sesuai posisi geografisnya. Pengamanan dan penanganan wilayah perbatasan dan pulau terluar merupakan bagian dari kepentingan pertahanan yang mendesak dan berhubungan langsung dengan kedaulatan negara yang harus ditangani melalui pendayagunaan fungsi pertahanan, baik militer maupun non-militer, secara terintegrasi. Eksistensi perbatasan dan pulau-pulau terluar sangat vital dalam penentuan batas wilayah Indonesia juga. Dalam konteks kedaulatan, pulau-pulau tersebut berfungsi sebagai titik pangkal penarikan batas wilayah (Zona Ekonomi Ekslusif) yang harus dijaga dan dilindungi (Simamora, 2013: 104-104).

\section{Dukungan Udara bagi Lantamal Ranai}

Faktor geografis Indonesia yang adalah negara kepulauan membuat continental based defense, dengan berfokus pada kekuatan Angkatan Darat menjadi tidak relevan. Indonesia sudah seharusnya menggunakan paradigma pertahanan kepulauan berdasarkan doktrin maritime based defense. Doktrin ini menekankan pada Angkatan Laut yang kuat dengan dukungan Angkatan Udara yang kuat juga. Maritime based defense harus mengkolaborasikan kekuatan Angkatan Laut dengan Angkatan Udara karena faktor geografis negara kepulauan membutuhkan respons cepat yang tidak mungkin dilakukan lewat darat (Indrawan, 2015: 207).

Dalam operasi militer bantuan udara juga sangat penting, apalagi untuk negara kepulauan seperti Indonesia. Angkatan Udara beroperasi secara taktis untuk memberikan bantuan bagi pasukan yang ada di darat maupun di laut. Bantuan yang diberikan dapat berbentuk pengintaian terhadap kedudukan musuh, mengarahkan atau memberikan bantuan tembakan, angkutan pasukan, perlengkapan, dan berbagai dukungan logistik lainnya. Dalam tingkatan strategis dapat berbentuk pertempuran udara antar pesawat tempur, pengeboman terhadap berbagai obyek vital musuh dan penghancuran sistem komunikasi musuh (Hakim, 2010: 140).

Di negara-negara maju, sinergi antara Angkatan Laut dan Angkatan Udara dibutuhkan sebagai first and 
second line of defense. Tidak ada Angkatan Laut yang kuat tanpa dukungan udara. Dalam perspektif penangkalan ancaman bagi negara yang berbasis kepulauan, yang dikirim pertama kali untuk menghadapi musuh adalah Angkatan Udara (first line). Jet-jet tempur tersebut harus diluncurkan dari kapal induk Angkatan Laut, bukan dari pangkalan di darat. Setelah mengirimkan pesawat tempur, armada Angkatan Laut bersiap di laut sebagai kekuatan pemukul atau berjaga melindungi wilayah kepulauan kita (second line) (Indrawan, 2015: 209).

Dalam mengorganisasikan pertahanan laut, TNI Angkatan Laut mengedepankan tiga pilar, yaitu (Hakim, 2011: 121):

1. Melakukan upaya penangkalan sejak di pangkalan.

2. Menghancurkan musuh di luar batas wilayah laut nasional, yakni di daerah:

a. Medan Pertahanan Penyanggah yang berada di luar garis batas ZEE Indonesia dan lapisan udara di atasnya. b. Medan

Pertahanan

Utama, sejak dari batas luar laut teritorial sampai dengan ZEE Indonesia dan lapisan udara di atasnya.

c. Medan Perlawanan, yakni daerah laut teritorial dan perairan kepulauan dan lapisan udara di atasnya.

3. Bila musuh tetap tidak terbendung, maka mereka akan dihancurkan di daratan sesuai doktrin Sishanta.

Pentingnya sinergi antara $\mathrm{AL}$ dengan AU terlihat dari penjelasan di atas, untuk itu peran dari Lanud Ranai di Natuna, Lanud Roesmin Nurjadin di Pekanbaru, dan Lanud Supadio di Pontianak menjadi menarik untuk di bahas sebagai supporting power untuk keberadaan Lantamal Ranai nantinya. Pentingnya kekuatan udara terlihat ketika China mulai "bermain" di wilayah Natuna, di mana saat itu TNI AU mulai menempatkan pesawat tempurnya di Lanud Ranai untuk berjaga-jaga.

Memang Lanud Ranai belum memiliki landasan pacu ideal untuk satu skuadron pesawat tempur, apalagi 
untuk pesawat Sukhoi SU-27 dan SU30, F-16 Fighting Falcon, serta pesawat KFX-IFX (sekarang disebut F-33) buatan Korea yang sudah dipesan dan akan menjadi bagian dari TNI AU. Untuk itu, runway Lanud Ranai akan diperlebar menjadi 42 meter dan panjang menjadi sekitar 3.000 meter, dari sebelumnya yang hanya panjang runway-nya hanya 2.560 meter dan lebar 32 meter untuk mengakomodasi satu skuadron penuh, yaitu antara 12-18 pesawat tempur (Batampos, 2016). Selain itu, penambahan hanggar juga diperlukan untuk menampung tambahan pesawat tempur.

Selain itu, dekatnya jarak Lanud Supadio dan Lanud Roesmin Nurjadin dengan Lanud Ranai membuat Lanud Ranai tidak perlu ditingkatkan statusnya menjadi Lanud tipe A. Lanud Ranai sendiri baru saja mengalami perubahan status pangkalan operasi menjadi tipe B dari sebelumnya tipe $\mathrm{C}$, untuk itu tidak perlu ditingkatkan menjadi tipe A. apalagi, Lanud Roesmin Nurjadin dan Supadio adalah dua dari lima Lanud dengan tipe A di bawah Komando Operasi Angkatan Udara (Koopsau) I.
Karena itu, penulis merasa lebih tepat jika Lanud Ranai dapat dioperasikan sebagai Forward Operating Base (FOB) jika katakanlah terjadi perang dengan China di Natuna. FOB adalah pangkalan taktis yang digunakan untuk mendukung dari Main Operating Base (MOB) jika terjadi perang. Jika memang menjadi FOB, fasilitas dan infrastruktur dari Lanud Ranai harus ditambah secara signifikan karena FOB memerlukan tidak hanya lapangan udara, tetapi juga rumah sakit, dan fasilitas pendukung lainnya.

Kembali menyinggung tentang Lantamal Ranai, MOB sendiri menurut penulis lebih tepat jika berada di Lantamal tersebut nantinya. Kombinasi dari kekuatan darat dari AL dan AD perlu ada di Lantamal Ranai sebagai persiapan untuk perang. Syarat dari MOB adalah harus bersifat permanen, sangat terlindungi, dapat mendukung secara permanen setiap pergerakan pasukan lewat laut atau udara, termasuk fasilitas latihan untuk pasukan (Global Security, 2015).

Kemudian, jika ada agresi militer di Natuna, dengan cepat skuadron pesawat tempur dari Lanud Supadio atau Lanud Roesmin 
Nurjadin bisa mencapai zona perang di sekitar Natuna. Lanud Ranai akan berguna sebagai supporting saja bagi skuadron pesawat tempur dari Lanud Supadio dan Roesmin Nurjadin. Di Lanud Supadio dan Roesmin Nurjadin bersiap tiga skuadron, yaitu Skuadron Udara 1 Elang Khatulistiwa di Supadio, serta Skuadron Udara 12 Panther Hitam dan Skuadron F-16 di Roesmin Nurjadin. Jika tensi meningkat dan ancaman perang nyata (immanent) di Natuna, tiga skuadron ini bisa dengan segera membantu Lanud Ranai dan Lantamal Ranai juga tentunya.

\section{Kesimpulan}

Kepulauan Natuna memang memiliki daya tarik bagi negaranegara lain karena potensi sumber daya alamnya yang sangat besar dan lokasinya yang strategis karena berdekatan dengan LCS. Karena itulah, China sebagai salah satu negara yang sedang bersengketa di LCS mulai untuk menganggu wilayah kedaulatan RI tersebut. Dengan meningkatnya aksi China di Natuna membuat kita harus lebih waspada dan bersiap menghadapi ancaman tersebut secara lebih serius, karena terbukti jika China memang merupakan ancaman bagi Indonesia di Natuna.

Untuk menghadapi ancaman tersebut, Lanal Ranai di Natuna harus ditingkatkan menjadi setingkat Lantamal agar bisa lebih efektif dan powerful dalam menjaga wilayah kedaulatan kita di Natuna. Setelah Lanal Ranai dianaikkan statusnya menjadi Lantamal, maka akan dibuat juga tiga Lanal yang berada di bawah Lantamal Ranai. Tiga lanal tersebut adalah Lanal Sekatung yang berada di pulau Sekatung, Lanal Subi Kecil yang berada di pulau Subi Kecil, dan Lanal Kepala yang berada di Pulau Kepala.

Memberdayakan pulau-pulau terluar di Indonesia untuk dijadikan pangkalan militer harus dilihat sebagai langkah memberdayakan pulau-pulau terluar, yang adalah bagian dari sistem pertahanan negara yang keberadaannya perlu dikelola sesuai posisi geografisnya. Dalam hal ini penting agar Indonesia memiliki kekuatan militer yang signifikan dan sifatnya permanen untuk ditempatkan di Natuna sebagai efek penggentar agar musuh tidak berani lagi "bermain-main" di wilayah kedaulatan kita. 


\section{DAFTAR PUSTAKA}

ABC. (2016, 31 Mei). Indonesia Seizes Chinese Fishing Boat and Crew in Escalating Natuna Island Row. Diakses 11 Juli 2017, dari http://www.abc.net.au/news/20 16-05-31/indonesia-seizeschinese-fishing-boat-andcrew/7461334

Antara Kepri. (2013, 23 Maret). Subi Laci Sejarah di Laut China Selatan. Diakses 22 Juli 2016, dari

http://www.antarakepri.com/be rita/24329/subi-laci-sejarah-di$\underline{\text { laut-china-selatan }}$

Batampos. (2016, 15 Januari). Pesawat Tempur Disiagakan Di Lanud Ranai. Diakses 26 Juli 2016 , darihttp://html.batampos.co.id/ $\underline{\mathrm{read} / 2016 / 01 / 15 / 32693 / \mathrm{Pesaw}}$ at-Tempur-Disiagakan-diLanud-Ranai

BBC. (2016, 12 Juli). Kapal Selam dan Rivalitas di Kedalaman Laut Cina Selatan. Diakses 22 Juli 2016, dari http://www.bbc.com/indonesia /dunia/2016/07/160711_dunia cina_militer_lautcinaselatan

CNN Indonesia. (2016, 23 Juni). Pangkalan Militer Dibangun di Deretan 'Gerbang' Indonesia. Diakses 22 Juli 2016 , dari http://www.cnnindonesia.com/ nasional/20160622170249-20-

140291/pangkalan-militerdibangun-di-deretan-gerbangindonesia/

Global Fire Power (2016). Total Navy Ship Strength by Country. Diakses 22 Juli 2016 dari http://www.globalfirepower.co $\underline{\mathrm{m} / \text { countries-comparison }}$ detail.asp?form=form\&country $1=$ china $\&$ country $2=$ indonesia $\&$ Submit=COMPARE

Global Security. (2015). Introduction-US Military Facilities. Diakses 23 Juli 2016 , dari http://www.globalsecurity.org/ military/facility/intro.htm

Hakim, C. (2010). Pelangi Dirgantara. Jakarta: Kompas.

Hakim, C. (2011). Pertahanan Indonesia: Angkatan Perang Negara Kepulauan. Jakarta: Red \& White Publishing. 
Indrawan, J., (2016, 23 April). Agresivitas Tiongkok di LTS. Harian Kompas.

Indrawan, J. (2015). Studi Strategis dan Keamanan. Depok: Nadi Pustaka. Jakarta Greater. (2015, 25 Maret). Alasan China Rebutan Natuna dengan Indonesia.Diakses 26 Juli 2016, dari http://jakartagreater.com/alasa n-china-rebutan-natunadengan-Indonesia.

Luhulima, C.P.F. (2011). Dinamika Asia Tenggara Menuju 2015. Yogyakarta: Pustaka Pelajar.

Maritime Awareness Project. (2016, 11 Juli). Traditional Fishing Grounds and China's Historic Rights Claims in the South China Sea. Diakses 20 Juli 2016 , dari

http://maritimeawarenessproje ct.org/2016/07/11/traditionalfishing-grounds-and-chinasclaims-in-the-south-china-sea/ Nytimes. (2016, 20 Juni). Indonesia Confirms Seizing Fishing Boat in South China Sea,Defying Beijing. Diakses 23 Juli 2016, dari http://www.nytimes.com/2016 /06/21/world/asia/indonesiasouth-china-sea-fishing.html. Okezone. (2016, 5 April). Pengembangan Lantamal TNI AL untuk Menyimpan Kapal Selam. Diakses 22 Juli 2016, dari

http://news.okezone.com/read/ 2016/04/05/337/1354920/peng embangan-lantamal-tni-aluntuk-menyimpan-kapal-selam Pemerintah Daerah Kabupaten Natuna. (2015). Potensi dan Peluang Investasi. Diakses 22 Juli 2016, dari http://www.natunakab.go.id/in vestasi.html

Rousseau, D., dan Garcia-Retamero, R. (2001). Identity, Power, and Threat Perception: A CrossNational Experimental Study. The Journal of Conflict Resolution, Vol. 51. No. 5.

Sindonews. (2016, 7 April). Indonesia Hendak Sebar Sistem Rudal Oerlikon Skyshield di Natuna. Diakses 26 Juli 2016, dari http://international.sindonews.com/rea d/1098978/40/indonesiahendak-sebar-sistem-rudaloerlikon-skyshield-di-natuna$\underline{1459990681}$ 
Simamora, P. (2013). Peluang dan Tantangan Diplomasi Keamanan Nasional

Pertahanan. Yogyakarta:

Graha Ilmu.

Speller, I., (2002). Delayed Reaction:

UK Maritime Expeditionary Capabilities and the Lesson of the Falklands Conflict. Journal of Defense and Security Analysis, Vol. 18, No.4.

Suara Karya. (2015, 27 Juni). Kontroversi Pulau Buatan Tiongkok. Diakses 24 Juli 2016, dari http://www.suarakarya.id/2015 /06/27/kontroversi-pulaubuatan-tiongkok-oleh-jerryindrawan.html

Tempo. (2016, 24 Maret). Kapal Selam RI dari Korea Dioperasikan, Ini Kecanggihannya. Diakses 22 Juli 2016, dari https://m.tempo.co/read/news/ 2016/03/24/078756663/kapalselam-ri-dari-koreadioperasikan-inikecanggihannya

Wirawan, H. dan Akbar Rayyan Subekti. (2012). Peningkatan Kapabilitas Militer China dan Implikasinya Terhadap 